\title{
Inactivation of EGFR/AKT signaling enhances TSA-induced ovarian cancer cell differentiation
}

\author{
GENBAO SHAO $^{1 *}$, WENSHENG LAI $^{1,2^{*}}$, XIAOLEI WAN ${ }^{3}$, JING XUE $^{1}$, YE WEI $^{1}$, JIE JIN $^{1}$, \\ LIUPING ZHANG ${ }^{1}$, QIONG LIN ${ }^{1}$, QIXIANG SHAO ${ }^{1}$ and SHENGQIANG ZOU ${ }^{2}$ \\ ${ }^{1}$ School of Medicine, Jiangsu University, Zhenjiang, Jiangsu 212013; ${ }^{2}$ Department of Intensive Care Unit, \\ The Affiliated Third People's Hospital of Jiangsu University, Zhenjiang, Jiangsu 212005; ${ }^{3}$ Department of Oncology, \\ The Affiliated People's Hospital of Jiangsu University, Zhenjiang, Jiangsu 212002, P.R. China
}

Received October 5, 2016; Accepted March 13, 2017

DOI: $10.3892 / o r .2017 .5556$

\begin{abstract}
Ovarian tumor is one of the most lethal gynecologic cancers, but differentiation therapy for this cancer is poorly characterized. Here, we show that thrichostatin A (TSA), the well known inhibitor of histone deacetylases (HDACs), can induce cell differentiation in HO8910 ovarian cancer cells. TSA-induced cell differentiation is characterized by typical morphological change, increased expression of the differentiation marker FOXA2, decreased expression of the pluripotency markers SOX2 and OCT4, suppressing cell proliferation, and cell cycle arrest in the $G_{1}$ phase. TSA also induces an elevated expression of cell cycle inhibitory protein $\mathrm{p} 21^{\text {Cip1 }}$ along with a decrease in cell cycle regulatory protein cyclin D1. Significantly, blockage of epidermal growth factor receptor (EGFR) signaling pathway with specific inhibitors of this signaling cascade promotes the TSA-induced differentiation of HO8910 cells. These results imply that the EGFR cascade inhibitors in combination with TSA may represent a promising differentiation therapy strategy for ovarian cancer.
\end{abstract}

\section{Introduction}

Epithelial ovarian cancer (EOC) is one of the leading causes of cancer death among women worldwide (1). Although continuous improvement in surgical techniques and initial response to chemotherapy has been made in the past few decades, recurrence still occurs in $\sim 70 \%$ of patients who underwent

Correspondence to: Dr Genbao Shao, School of Medicine, Jiangsu University, 301 Xuefu Road, Zhenjiang, Jiangsu 212013, P.R. China

E-mail: gbshao07@ujs.edu.cn

Dr Shengqiang Zou, Department of Intensive Care Unit, The Affiliated Third People's Hospital of Jiangsu University, 300 Daijiamen Road, Zhenjiang, Jiangsu 212005, P.R. China

E-mail: 1210xyz@163.com

${ }^{*}$ Contributed equally

Key words: thrichostatin A, epidermal growth factor receptor, AKT, cell differentiation, ovarian cancer the first-line chemotherapy within 18 months $(2,3)$. The 5-year survival rate remains poor at $30.6 \%$ for patients with advanced EOC $(4,5)$. Thus, it is of great clinical importance to develop effective chemotherapy strategies for EOC.

Differentiation therapy has emerged as a potential chemotherapy strategy against tumors (6). The clinical effectiveness of differentiation therapy has been demonstrated in acute promyelocytic leukemia (APL) using all-trans-retinoic acid as an inducer (7). Recently, arsenic trioxide $\left(\mathrm{As}_{2} \mathrm{O}_{3}\right)$, a well-established human carcinogen, has also proven to be a differentiation agent in the treatment of APL patients (8). Of interest, such effects are not reliably reproduced in solid tumors. Differentiation agents for ovarian cancer remain elusive.

Thrichostatin A (TSA), a hydroxamate-type histone deacetylase inhibitor, can promote histone acetylation by remodeling of chromatin architecture, and induce cell differentiation (9). TSA also catalyzes the acetylation of non-histone proteins, which may regulate signaling related to tumorigenesis $(10,11)$. Accumulated evidence indicates that TSA can activate AKT signaling pathway (12). Overexpression of epidermal growth factor receptor (EGFR), the upstream effector of AKT, has been associated with increased chemoresistance and poorer clinical outcome $(13,14)$. However, it is unclear whether TSA transactivates the EGFR/AKT pathway in EOC, and whether the blockage of this pathway can potentiate the effect of TSA on EOC differentiation.

In this study, we demonstrate that TSA can induce cellular differentiation in HO8910 ovarian cancer cells. We show that TSA transiently activates EGFR/AKT signaling pathway, causing expression of differentiation-related genes, and blocking this pathway sensitizes HO8910 cells to TSA. This implies that a combination of EGFR/AKT pathway inhibitors with TSA may represent a better differentiation therapy strategy for ovarian cancer.

\section{Materials and methods}

Cell line and culture. Human ovarian cancer cell line, HO8910, was kindly provided by Dr Qixiang Shao of Jiangsu University (Zhenjiang, China). The HO8910 cells were derived from ascites of ovarian adenocarcinoma patients. The cells 


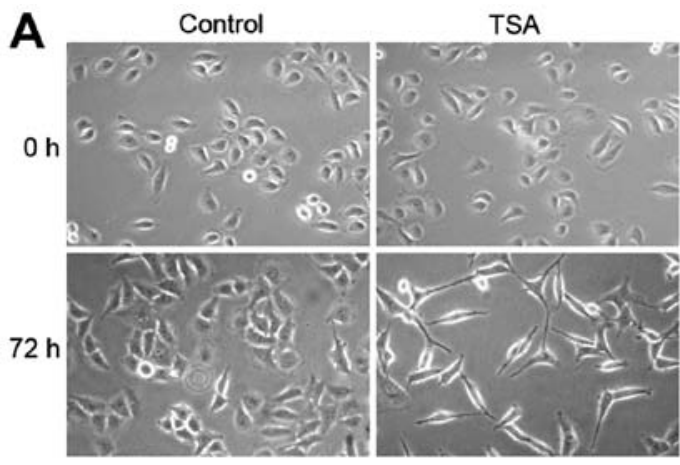

B

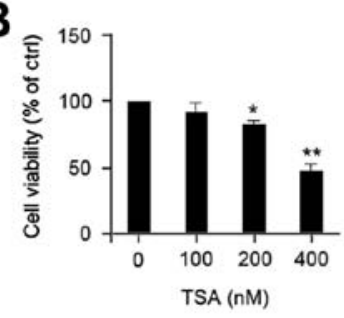

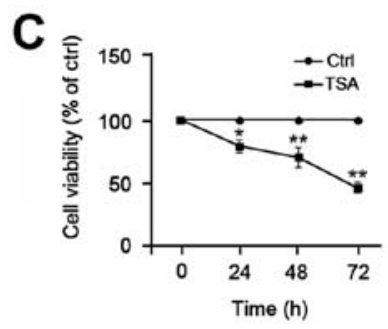

$\mathbf{E}$
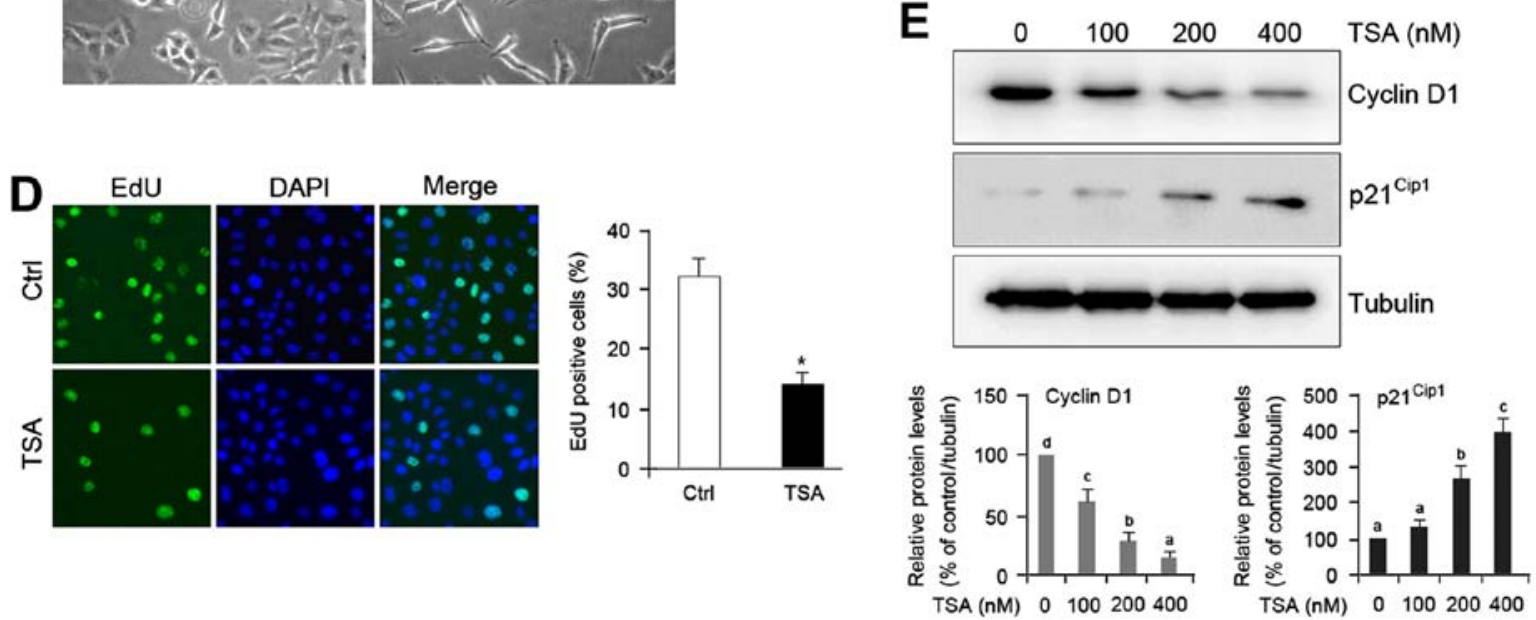

Figure 1. TSA induces cell differentiation and proliferation inhibition of HO8910 ovarian cancer cells. (A) Cells were incubated without or with $200 \mathrm{nM}$ thrichostatin A (TSA) for the indicated times (magnification, x200). (B) Cells were treated with different doses of TSA for 48 h, and cell proliferation was analyzed by CCK-8 assay. (C) Cells were treated with $200 \mathrm{nM}$ TSA for the indicated times, after which cell proliferation was detected via CCK-8 assay. (D) Cells were treated without or with TSA $200 \mathrm{nM}$ TSA for $48 \mathrm{~h}$, and then incubated with 50 mM 5-ethynyl-2'-deoxyuridine (EdU) for $2 \mathrm{~h}$ and the nuclei were stained with DAPI. Representative micrographs (left panel, magnification, x400) and quantification (right panel) of EdU-incorporating cells in control and TSA-treated cells. Green, EdU; blue, DAPI. The error bars represent mean \pm SEM $(n=3)$. Statistical differences compared with the controls are given as ${ }^{*} \mathrm{P}<0.05$ and ${ }^{* *} \mathrm{P}<0.01$ (Student's t-test). (E) Cells were treated with different doses of TSA for 48 h. Total protein was extracted and blotted with antibodies against cyclin D1, p21 $1^{\text {Cip1 }}$, and $\alpha$-tubulin. The error bars represent the mean \pm SEM $(n=3)$. Values within the same row with different superscripted letters are significantly different, $\mathrm{P}<0.05$ (one-way ANOVA).

were maintained for no longer than 3 months as described previously (15).

Antibodies and reagents. EGFR, phospho-EGFR (Tyr992), AKT, phospho-AKT(Ser473), FOXA2, and acetyl-histone H3K9 antibodies were purchased from Cell Signaling Technology (Danvers, MA, USA). $\alpha$-tubulin and secondary antibodies were procured from Bioworld Technology (Shanghai, China). OCT4, SOX2, p21 Cip1, cyclin D1, and histone H3 antibodies were obtained from Abcam (Cambridge, MA, USA). The EGFR inhibitor AG1478, AKT inhibitor A6730, and HDAC inhibitor TSA were procured from Sigma (St. Louis, MO, USA). TSA and A6730 were dissolved in ethanol as stocks (6.6 $\mathrm{mM})$ and dimethyl sulfoxide as stocks $(20 \mathrm{mM})$, respectively.

Drug treatment. In TSA experiments, HO8910 cells were incubated with 100, 200, and $400 \mathrm{nM}$ TSA and harvested at $48 \mathrm{~h}$. When the expression of differentiation-related genes was examined, cells were harvested at $24 \mathrm{~h}$. For cotreatment of TSA and EGFR pathway inhibitors, cells were incubated with $200 \mathrm{nM}$ TSA in presence of AG1478 $(10 \mu \mathrm{M})$ or A6730 $(20 \mu \mathrm{M})$ for $24 \mathrm{~h}$.

Morphological evaluation. The morphological changes in TSA-treated cells were observed during a 72-h time course with a light microscope (Olympus, Tokyo, Japan), and images were obtained via a CCD camera (Olympus).

Histone protein and whole-cell extraction and western blotting. Histones were prepared using the bioepitope nuclear and cytoplasmic extraction kit (Bioworld Technology) following the manufacturer's protocol. Total cellular proteins were isolated directly from cultures in 100-mm Petri dishes after being washed with ice-cold PBS and the addition of $200 \mu 1$ Cell and Tissue Protein Extraction reagent (Kangchen Biotech, Shanghai, China), containing protease inhibitor and phosphatase inhibitor cocktails (Roche). Antibodies against OCT4 (1:5,000), SOX2 (1:5,000), FOXA2 (1:1,000), cyclin D1 $(1: 10,000)$, p21 ${ }^{\text {Cip1 }}(1: 3,000)$, EGFR $(1: 1,000)$, p-EGFR (1:600), AKT (1:1,000), p-AKT (1:800), $\alpha$-tubulin $(1: 1,000)$, and histone H3 $(1: 2,000)$ were used for western blot analysis, which was performed as described previously (16).

Cell proliferation assays. The cell proliferation assays were performed using CCK-8 and EdU. Briefly, HO8910 cells $\left(5 \times 10^{3}\right)$ were seeded in 96-well plates, and then treated with TSA for 24, 48, and $72 \mathrm{~h}$. For CCK-8 analysis, the cells were incubated with $1 / 10$ volume of CCK- 8 for $2 \mathrm{~h}$. The plates were then read at $450 \mathrm{~nm}$ with a Bio-Rad model 680 microplate reader $(\mathrm{Richmond}, \mathrm{CA}, \mathrm{USA})$. The cell proliferation rate = $\mathrm{OD}_{\text {experiment }} / \mathrm{OD}_{\text {control }}$ x $100 \%$. For EdU assay, HO8910 cells 

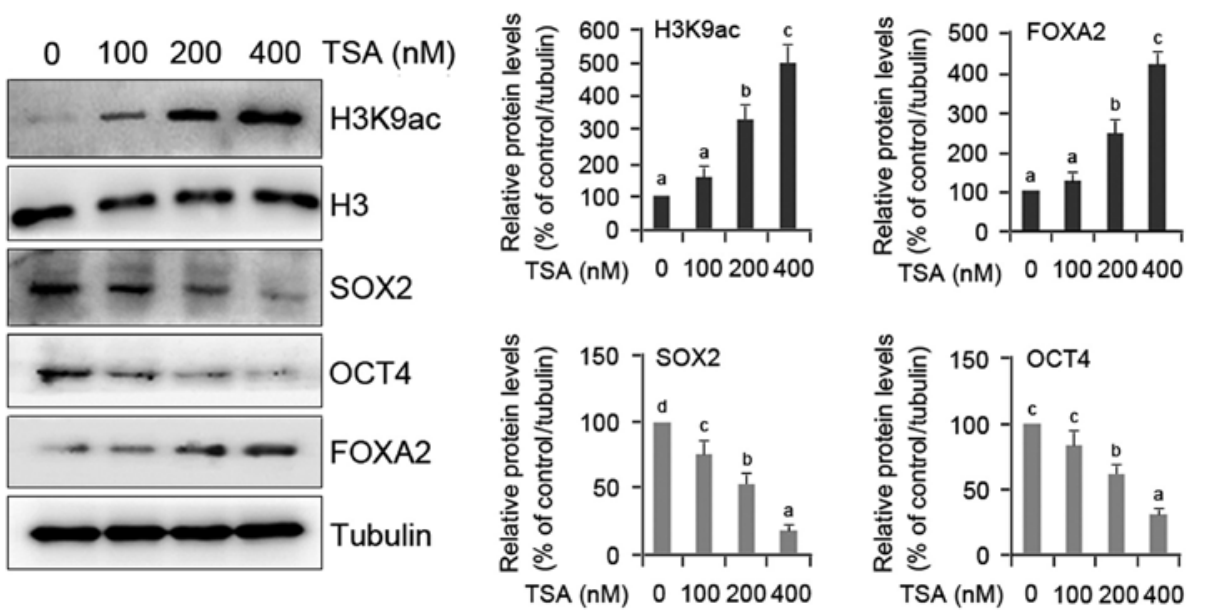

Figure 2. Effects of TSA on expression of SOX2, OCT4, and FOXA2 proteins in HO8910 cells. Cells were treated with different doses of TSA for $24 \mathrm{~h}$. Protein levels were detected via western blotting in whole-cell extracts (SOX2, OCT4, and FOXA2) or histone protein extracts (H3K9ac and histone H3) from the above treated cells. H3K9ac, H3K9 acetylation. Histone H3 and $\alpha$-tubulin, loading control. The error bars represent the mean \pm SEM ( $n=3)$. Values within the same row with different letters are significantly different, $\mathrm{P}<0.05$ (one-way ANOVA).

were treated with $200 \mathrm{nM}$ TSA for $48 \mathrm{~h}$, and then incubated with EdU $(50 \mathrm{mM})$ for $2 \mathrm{~h}$, after which the nuclei were stained with DAPI. The images were photographed by an Olympus inverted microscope system.

Cell cycle analysis. The effect of TSA on HO8910 cell cycle phase distribution was determined by flow cytometry. HO8910 cells were fixed in $70 \%$ ethanol for $30 \mathrm{~min}$ at $4^{\circ} \mathrm{C}$. The cells were then incubated with propidium iodide $(50 \mu \mathrm{g} / \mathrm{ml})$ for $30 \mathrm{~min}$ at $37^{\circ} \mathrm{C}$, after which the fluorescence was measured with a flow cytometer (BD Biosciences, Heidelberg, Germany).

Statistical analysis. Data are presented as the mean \pm SEM. Statistical significance was calculated by Student's t-test or ANOVA, and values of $\mathrm{P}<0.05$ were considered statistically significant.

\section{Results}

TSA induces morphological changes of HO8910 cells. To elucidate the effect of TSA on ovarian cancer cell differentiation, we examined the morphology of HO8910 cells treated with or without TSA. Microscopic observation of control cells revealed round, stellate-like appearance and growth in clusters. Unlike the morphology of control, a majority of TSA-treated cells exhibited spindle shape and much longer, fine, tapering processes (Fig. 1A). Treatment with TSA also caused a decrease in cell density (Fig. 1A), which suggests that TSA may impede proliferation of HO8910 cells. Consistent with this prediction, we found that TSA treatment caused a notable reduction in cell proliferation rate compared with the control in a dose- and time-dependent manner (Fig. 1B and C). The suppressive effect of TSA on cell proliferation was further confirmed by 5-ethynyl-2'-deoxyuridine (EdU) assay (Fig. 1D).

To identify the mechanism of action of TSA in decreasing cell proliferation, we undertook cell cycle analysis with propidium iodide to label DNA. Table I reveals that treatment with TSA for $48 \mathrm{~h}$ led to an accumulation of HO8910 cells in the $\mathrm{G}_{0} / \mathrm{G}_{1}$ phase $(60.2$ vs. $82.8 \%, \mathrm{P}<0.05)$ and a concomitant
Table I. TSA causes cell cycle arrest in $\mathrm{G}_{0} / \mathrm{G}_{1}$ phase in $\mathrm{HO} 910$ cells.

\begin{tabular}{lcc}
\hline & Control & TSA $(n M)$ \\
\cline { 2 - 3 } Groups & 0 & 200 \\
\hline $\mathrm{G}_{0} / \mathrm{G}_{1}$ & $60.2 \pm 1.8$ & $82.8 \pm 1.7^{\text {a }}$ \\
$\mathrm{S}$ & $26.7 \pm 1.3$ & $3.8 \pm 0.6^{\mathrm{b}}$
\end{tabular}

Data are presented as mean \pm SEM $(n=3)$ for control and TSA groups. ${ }^{\mathrm{a}} \mathrm{P}<0.05$ and ${ }^{\mathrm{b}} \mathrm{P}<0.01$ compared with control (Student's t-test), respectively.

decrease in the S-phase cell fraction (26.7 vs. $3.8 \%, \mathrm{P}<0.01)$. The TSA-induced cell cycle arrest was further confirmed by examining the expression of cell cycle regulatory protein cyclin D1 in HO8910 cells. Western blot analysis indicated that TSA treatment exhibited decrease of cyclin D1 levels and increase of $\mathrm{p} 21^{\mathrm{Cip} 1}$ protein (Fig. 1E). These data suggest that TSA induces cell differentiation and proliferation inhibition of HO8910 cells.

Molecular evidence of TSA-induced differentiation of HO8910 cells. To verify the role of TSA in HO8910 cell differentiation, two groups of genes including FOXA2 as differentiation marker gene, and SOX2 and OCT4 as pluripotency marker genes were evaluated quantitatively. FOXA2 gene was evaluated because it plays important roles in regulating the expression of genes involved in cell differentiation in a number of different organs (17), and is essential for differentiation and development of glands in mouse uterus (18). A dose-dependent upregulation of FOXA2 protein and H3K9 acetylation was observed in TSA-treated cells compared with the controls (Fig. 2). In contrast, the expression of SOX2 and OCT4 proteins was notably restrained by TSA (Fig. 2). This molecular evidence confirms that TSA actually induces the differentiation of HO8910 cells. 


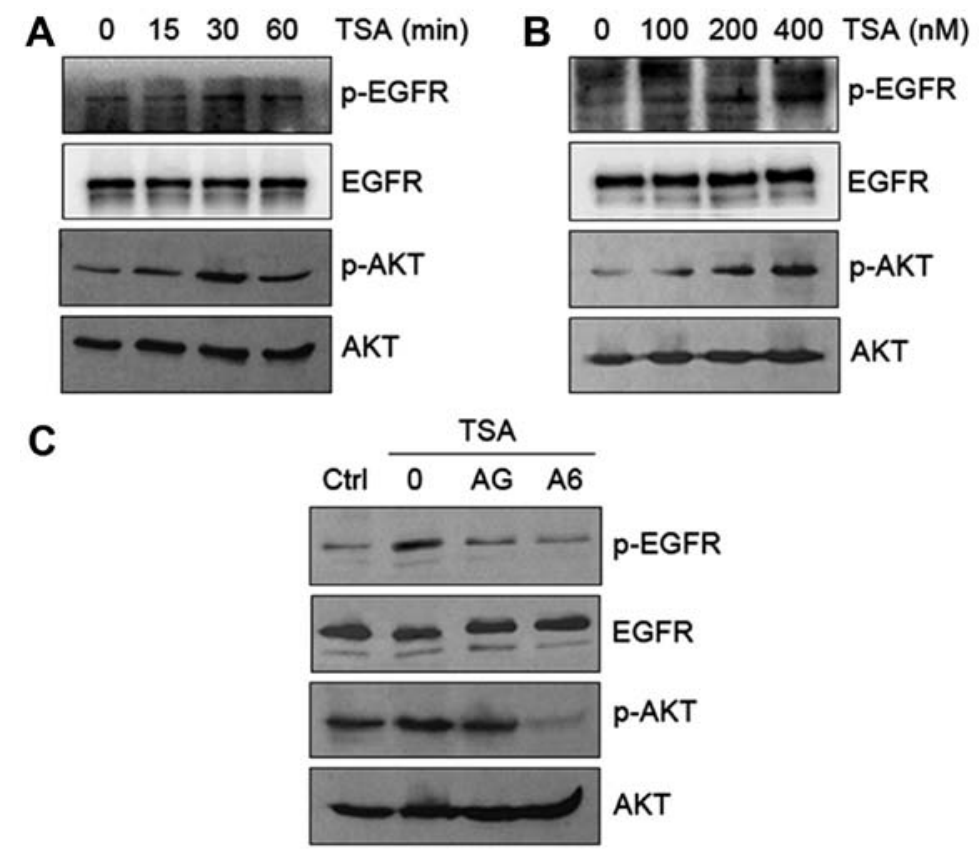

Figure 3. TSA activates EGFR/AKT signaling pathway in HO8910 cells. (A) Cells were treated with $200 \mathrm{nM}$ TSA for the indicated times. The harvested cells were then subjected to western blotting and probed for phosphorylated EGFR (Tyr992) and total EGFR, and phosphorylated AKT (Ser473) and total AKT. (B) Cells were treated with different doses of TSA for $30 \mathrm{~min}$, after which the protein levels of p-EGFR, EGFR, p-AKT, and AKT were detected via western blotting. (C) Cells were pretreated with EGFR inhibitor AG1478 $(10 \mu \mathrm{M})$ or AKT inhibitor A6730 $(20 \mu \mathrm{M})$ for $2 \mathrm{~h}$ prior to the addition of TSA $(200 \mathrm{nM})$ for 30 min. Protein levels of p-EGFR, EGFR, p-AKT, and AKT were detected via western blotting.
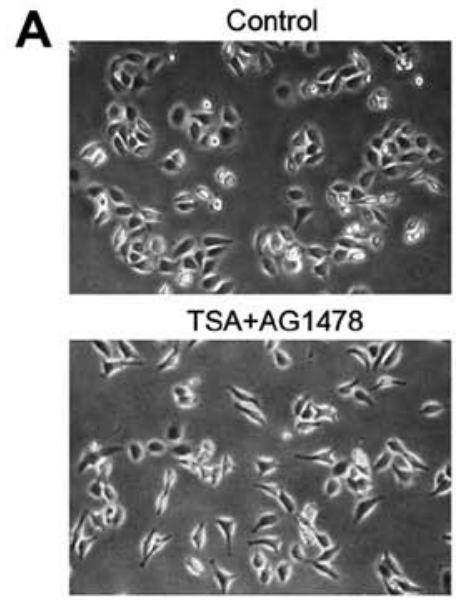

TSA

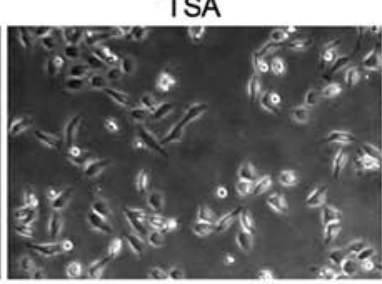

$\mathrm{TSA}+\mathrm{A} 6730$

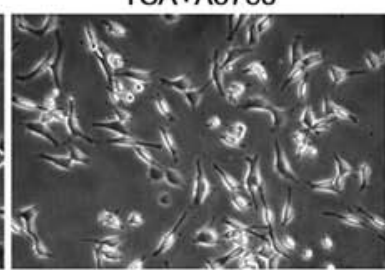

B

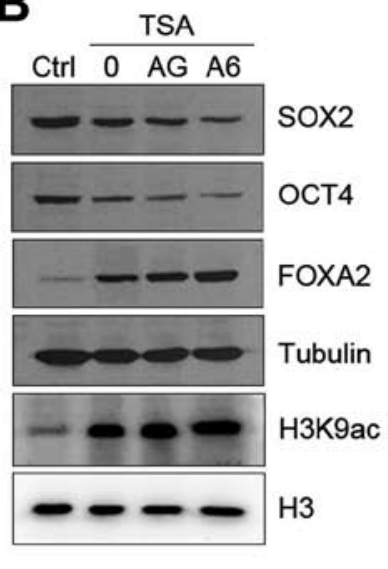

C

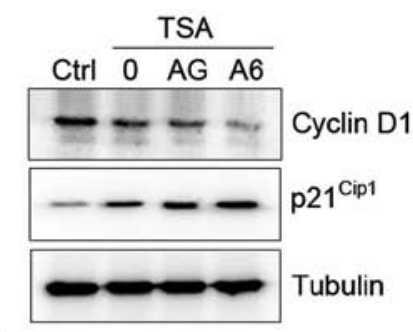

Figure 4. Inhibition of EGFR/AKT signaling pathway enhances TSA-induced differentiation of HO8910 cells. Cells were treated with TSA (200 nM) alone or in combination with AG1478 $(10 \mu \mathrm{M})$ or A6730 $(20 \mu \mathrm{M})$ for $24 \mathrm{~h}$. Cell morphology was photographed under a phase-contrast microscopy (A), and protein levels were detected via western blotting in whole-cell extracts (SOX2, OCT4, FOXA2, cyclin D1, p2 ${ }^{\text {Cip1 }}$, and $\alpha$-tubulin) or histone protein extracts (H3K9ac and histone $\mathrm{H} 3$ ) from the above treated cells (B and C). $\alpha$-tubulin and histone H3, loading control.

Transactivation of EGFR/AKT pathway by TSA in HO8910 cells. Since EGFR expression strongly correlates with tumor resistance to cytotoxic agents (19), EGFR could be a potential target for anticancer therapy. To decipher whether TSA transactivates EGFR in HO8910 cells, we first examined phosphorylation of EGFR and AKT in response to TSA. Our results indicated that TSA caused a time- and dose-dependent increase in phosphorylation of EGFR (Tyr992) and AKT (Ser473) (Fig. 3A and B). The TSA-induced phosphorylation of EGFR and AKT occurred at 15 min and peaked at 30 min (Fig. 3A). The observed changes in EGFR and AKT phosphorylation were reversed in HO8910 cells in response to
EGFR inhibitor AG1478 and AKT inhibitor A6730 (Fig. 3C). These data suggest that TSA activates EGFR phosphorylation and subsequent activation of downstream AKT signaling.

Inhibition of EGFR/AKT pathway promotes TSA-induced differentiation of HO8910 cells. The above data indicate that TSA induces ovarian cancer cell differentiation prompted us to test whether the EGFR/AKT pathway was involved in this process. HO8910 cells treated with either AG1478 or A6730 markedly promoted TSA-induced cell differentiation with morphological changes (Fig. 4A). To determine the mechanism by which inhibition of the EGFR/AKT pathway enhances cell 
Table II. Inhibition of EGFR/AKT signaling pathway enhances TSA-induced $\mathrm{G}_{0} / \mathrm{G}_{1}$-phase cell cycle arrest in HO8910 cells.

\begin{tabular}{lcccc}
\hline Groups & Control & TSA & TSA+AG1478 & TSA+A6730 \\
\hline $\mathrm{G}_{0} / \mathrm{G}_{1}$ & $58.3 \pm 1.2^{\mathrm{c}}$ & $79.7 \pm 2.4^{\mathrm{b}}$ & $85.6 \pm 1.1^{\mathrm{a}}$ & $89.5 \pm 2.5^{\mathrm{a}}$ \\
$\mathrm{S}$ & $27.1 \pm 1.3^{\mathrm{a}}$ & $3.9 \pm 0.7^{\mathrm{b}}$ & $3.8 \pm 1.6^{\mathrm{b}}$ & $2.6 \pm 1.8^{\mathrm{b}}$ \\
\hline
\end{tabular}

Data are presented as mean \pm SEM $(n=3)$ for control, TSA alone, and in combination with EGFR inhibitor AG1478 (TSA+AG1478) or AKT inhibitor A6730 (TSA+A6730) groups. Values with different superscript letters represent statistically significant differences between $\mathrm{G}_{0} / \mathrm{G}_{1}$ and $\mathrm{S}$ phases, $\mathrm{P}<0.05$ (one-way ANOVA).

differentiation, we tested the expression of differentiationrelated genes in HO8910 cells. As expected, combination of TSA and AG1478 or A6730 drastically reduced the levels of SOX2 and OCT4 and increased the expression of FOXA2 in the cells (Fig. 4B). Both inhibitors also caused an increase in global levels of H3K9 acetylation (Fig. 4B).

Next, we tested the effect of TSA on cell cycle regulation when EGFR/AKT signaling pathway was inhibited. Treatment with AG1478 or A6730 decreased the levels of cyclin D1 and increased the expression of $\mathrm{p} 21^{\mathrm{Cip} 1}$ in HO8910 cells in response to TSA (Fig. 4C). Furthermore, combination treatment with TSA and AG1478 or A6730 led to an accumulation of cells in $\mathrm{G}_{0} / \mathrm{G}_{1}$ phase in comparison to TSA alone (Table II). Collectively, our data suggest that TSA plays a role in cell differentiation and that blockage of EGFR/AKT signaling pathway enhances TSA-induced differentiation.

\section{Discussion}

Epigenetic regulation of gene expression represents a promising strategy for differentiation-based therapy (20). Histone acetylation is determined by antagonistic actions of histone acetyltransferases (HATs) and HDACs $(21,22)$. A variety of HDAC inhibitors have been demonstrated to induce differentiation in some solid tumors (23). In this study, we characterized the effect of TSA, one of the potent HDAC inhibitors, on cell differentiation of ovarian tumors. We show that TSA increases the levels of H3K9 acetylation, and induces cell differentiation in HO8910 ovarian cancer cells with marked morphological transformation. Molecular evidence for differentiation is demonstrated by decreased expression of SOX2, OCT4, and cyclin D1, and increased expression of FOXA2 and p21 ${ }^{\text {Cip1 }}$. Significantly, blockage of EGFR/AKT signaling pathway enhances the TSA-induced differentiation of HO8910 cells.

Cancer stem cells (CSCs) that retain both the self-renewal and differentiation, contributes to tumorigenesis and chemotherapy resistance in malignancies $(24,25)$. The poor clinical outcome in patients with ovarian cancer may be due to the existence of CSCs (24). Overexpression of OCT4 and SOX2 is detected more frequently in poorly differentiated cancers than in well-differentiated ones, and is not detected in paraneoplastic tissues and benign tumors $(26,27)$. OCT4 is also overexpressed in CSCs and is closely related to chemotherapy resistance (28), suggesting that OCT4 is a pluripotency marker for CSCs. In addition, FOXA2 is a sensitive marker of CSC and cancer cell differentiation $(29,30)$, and it was reported that apicidin, another HDAC inhibitor, upregulates FOXA2 expression, leading to enhanced differentiation of dopaminergic neurons (29). Our current data demonstrated that TSA may promote cell differentiation through upregulation of FOXA2 expression and downregulation of OCT4 and SOX2 expression. Strikingly, inhibition of EGFR/AKT signaling pathway enhances the induction of cell differentiation and FOXA2 expression in response to TSA. These data suggest that the EGFR signaling may overcome the TSA-induced cell differentiation through downregulation of FOXA2 expression.

The Cdk inhibitor p21 ${ }^{\mathrm{Cipl}}$ plays a critical role in mediating proliferation inhibition and acts as a cell cycle arrest point (31). There is accumulating evidence linking $\mathrm{p} 21^{\mathrm{Cipl}}$ to carcinogenesis in many tumors, including ovarian cancer (32-34). The increase in $\mathrm{p} 21^{\mathrm{Cip} 1}$ could be associated with increased cell cycle suppression by TSA in our study. The concomitant reduction in cyclin D1 expression may cooperate with induction of $\mathrm{p} 21^{\mathrm{Cipl}}$ to arrest the cell cycle, and thus contribute to proliferation inhibition induced by TSA. The upregulation of p21 ${ }^{\mathrm{Cip} 1}$ might lead to preferential cell cycle arrest upon TSA treatment.

HDACi in combination with chemotherapy has been confirmed to give better clinical outcome than chemotherapy alone $(35,36)$. One potential strategy to increase treatment efficacy is the combination of HDACi with other novel agents. A recent study found that inhibition of EGFR/PI3K signaling pathway enhanced TSA-induced cell death and inhibited cell migration (37). The EGFR/PI3K pathway also mediates Lewis(y)-induced cell proliferation (38). In this study, the reduction of cell proliferation was additionally enhanced when TSA was combined with the EGFR/AKT pathway inhibitors AG1478 or A6730, in accordance with a previous report (37). This finding suggests that EGFR signaling pathway could be a target for improving therapeutic efficacy of TSA.

Here, we provide a link between the inhibition of EGFR signaling and the differentiation effect of TSA on HO8910 cells. Our data indicate that TSA transactivates the EGFR signaling pathway, which overcomes the TSA-induced differentiation of HO8910 cells via regulation of differentiation-related genes. Blockage of the EGFR signaling pathway by AG1478 or A6730 enhances the TSA-mediated cell differentiation. Although TSA is an epigenetic regulator, the present study did not establish a mechanistic link between TSA and epigenetic regulation of cell differentiation in HO8910 cells. Further studies are needed to determine how TSA activates the EGFR pathway in an epigenetic manner and how such activation affects ovarican cancer cell differentiation.

\section{Acknowledgements}

This study was supported by National Natural Science Foundation of China (81170573).

\section{References}

1. Romero I and Bast RC Jr: Minireview: human ovarian cancer: biology, current management, and paths to personalizing therapy. Endocrinology 153: 1593-1602, 2012.

2. Lopez J, Banerjee S and Kaye SB: New developments in the treatment of ovarian cancer - future perspectives. Ann Oncol 24 (Suppl 10): X69-X76, 2013. 
3. Kim A, Ueda Y, Naka T and Enomoto T: Therapeutic strategies in epithelial ovarian cancer. J Exp Clin Cancer Res 31: 14, 2012.

4. Ferlay J, Parkin DM and Steliarova-Foucher E: Estimates of cancer incidence and mortality in Europe in 2008. Eur J Cancer 46: 765-781, 2010.

5. Leitao MM Jr and Chi DS: Surgical management of recurrent ovarian cancer. Semin Oncol 36: 106-111, 2009.

6. Leszczyniecka M, Roberts T, Dent P, Grant S and Fisher PB: Differentiation therapy of human cancer: Basic science and clinical applications. Pharmacol Ther 90: 105-156, 2001.

7. Huang ME, Ye YC, Chen SR, Chai JR, Lu JX, Zhoa L, Gu LJ and Wang ZY: Use of all-trans retinoic acid in the treatment of acute promyelocytic leukemia. Blood 72: 567-572, 1988.

8. Kinjo K, Kizaki M, Muto A, Fukuchi Y, Umezawa A, Yamato K Nishihara T, Hata J, Ito M, Ueyama Y, et al: Arsenic trioxide $\left(\mathrm{As}_{2} \mathrm{O}_{3}\right)$-induced apoptosis and differentiation in retinoic acid-resistant acute promyelocytic leukemia model in hGMCSF-producing transgenic SCID mice. Leukemia 14: 431-438, 2000.

9. Yamashita Y, Shimada M, Harimoto N, Rikimaru T, Shirabe K, Tanaka S and Sugimachi K: Histone deacetylase inhibitor trichostatin A induces cell-cycle arrest/apoptosis and hepatocyte differentiation in human hepatoma cells. Int J Cancer 103 : 572-576, 2003

10. Rosato RR and Grant S: Histone deacetylase inhibitors in clinical development. Expert Opin Investig Drugs 13: 21-38, 2004.

11. Buchwald M, Krämer OH and Heinzel T: HDACi - targets beyond chromatin. Cancer Lett 280: 160-167, 2009.

12. Eickhoff B, Germeroth L, Stahl C, Köhler G, Rüller S, Schlaak M and van der Bosch J: Trichostatin A-mediated regulation of gene expression and protein kinase activities: Reprogramming tumor cells for ribotoxic stress-induced apoptosis. Biol Chem 381: $1127-1132,2000$

13. Freudlsperger C, Burnett JR, Friedman JA, Kannabiran VR, Chen Z and Van Waes C: EGFR-PI3K-AKT-mTOR signaling in head and neck squamous cell carcinomas: Attractive targets for molecular-oriented therapy. Expert Opin Ther Targets 15: 63-74, 2011.

14. Lassus H, Sihto H, Leminen A, Joensuu H, Isola J, Nupponen NN and Butzow R: Gene amplification, mutation, and protein expression of EGFR and mutations of ERBB2 in serous ovarian carcinoma. J Mol Med (Berl) 84: 671-681, 2006.

15. Shao G, Wang J, Li Y, Liu X, Xie X, Wan X, Yan M, Jin J, Lin Q, Zhu H, et al: Lysine-specific demethylase 1 mediates epidermal growth factor signaling to promote cell migration in ovarian cancer cells. Sci Rep 5: 15344, 2015.

16. Li Y, Wan X, Wei Y, Liu X, Lai W, Zhang L, Jin J, Wu C, Shao Q, Shao G, et al: LSD1-mediated epigenetic modification contributes to ovarian cancer cell migration and invasion. Oncol Rep 35: 3586-3592, 2016.

17. Kaestner KH: The FoxA factors in organogenesis and differentiation. Curr Opin Genet Dev 20: 527-532, 2010.

18. Jeong JW, Kwak I, Lee KY, Kim TH, Large MJ, Stewart CL, Kaestner KH, Lydon JP and DeMayo FJ: Foxa2 is essential for mouse endometrial gland development and fertility. Biol Reprod 83: 396-403, 2010.

19. Akimoto T, Hunter NR, Buchmiller L, Mason K, Ang KK and Milas L: Inverse relationship between epidermal growth factor receptor expression and radiocurability of murine carcinomas. Clin Cancer Res 5: 2884-2890, 1999.

20. Wang LT, Liou JP, Li YH, Liu YM, Pan SL and Teng CM: A novel class I HDAC inhibitor, MPT0G030, induces cell apoptosis and differentiation in human colorectal cancer cells via $\mathrm{HDAC} 1 /$ PKC $\delta$ and E-cadherin. Oncotarget 5: 5651-5662, 2014.

21. Liu H, Wu H, Wang Y, Wang Y, Wu X, Ju S and Wang X: Inhibition of class II histone deacetylase blocks proliferation and promotes neuronal differentiation of the embryonic rat neural progenitor cells. Acta Neurobiol Exp (Wars) 72: 365-376, 2012.
22. Kretsovali A, Hadjimichael $\mathrm{C}$ and Charmpilas N: Histone deacetylase inhibitors in cell pluripotency, differentiation, and reprogramming. Stem Cells Int 2012: 184154, 2012.

23. Cruz FD and Matushansky I: Solid tumor differentiation therapy - is it possible? Oncotarget 3: 559-567, 2012.

24. Ciurea ME, Georgescu AM, Purcaru SO, Artene SA, Emami GH, Boldeanu MV, Tache DE and Dricu A: Cancer stem cells Biological functions and therapeutically targeting. Int J Mol Sci 15: 8169-8185, 2014

25. Kwon MJ and Shin YK: Regulation of ovarian cancer stem cells or tumor-initiating cells. Int J Mol Sci 14: 6624-6648, 2013.

26. Li X, Wang J, Xu Z, Ahmad A, Li E, Wang Y, Qin S and Wang Q: Expression of Sox 2 and Oct 4 and their clinical significance in human non-small-cell lung cancer. Int J Mol Sci 13: 7663-7675, 2012.

27. Ge N, Lin HX, Xiao XS, Guo L, Xu HM, Wang X, Jin T, Cai XY, Liang Y, Hu WH, et al: Prognostic significance of Oct4 and Sox2 expression in hypopharyngeal squamous cell carcinoma. J Transl Med 8: 94, 2010

28. Lin H, Sun LH, Han W, He TY, Xu XJ, Cheng K, Geng C, Su LD, Wen H, Wang XY, et al: Knockdown of OCT4 suppresses the growth and invasion of pancreatic cancer cells through inhibition of the AKT pathway. Mol Med Rep 10: 1335-1342, 2014.

29. Bang SY, Kwon SH, Yi SH, Yi SA, Park EK, Lee JC, Jang CG, You JS, Lee SH and Han JW: Epigenetic activation of the Foxa2 gene is required for maintaining the potential of neural precursor cells to differentiate into dopaminergic neurons after expansion. Stem Cells Dev 24: 520-533, 2015.

30. Zhang X, Lu F, Wang J, Yin F, Xu Z, Qi D, Wu X, Cao Y, Liang W, Liu Y, et al: Pluripotent stem cell protein Sox 2 confers sensitivity to LSD1 inhibition in cancer cells. Cell Rep 5: 445-457, 2013

31. Sherr CJ and Roberts JM: CDK inhibitors: Positive and negative regulators of G1-phase progression. Genes Dev 13: 1501-1512, 1999.

32. Weiss RH: $\mathrm{p} 21^{\mathrm{Waf} 1 / \mathrm{Cipl}}$ as a therapeutic target in breast and other cancers. Cancer Cell 4: 425-429, 2003.

33. Jackson RJ, Adnane J, Coppola D, Cantor A, Sebti SM and Pledger WJ: Loss of the cell cycle inhibitors p21(Cip1) and p27(Kip1) enhances tumorigenesis in knockout mouse models. Oncogene 21: 8486-8497, 2002.

34. Bali A, O'Brien PM, Edwards LS, Sutherland RL, Hacker NF and Henshall SM: Cyclin D1, p53, and p21 $1^{\text {Waf1/Cip1 }}$ expression is predictive of poor clinical outcome in serous epithelial ovarian cancer. Clin Cancer Res 10: 5168-5177, 2004.

35. Ahrens TD, Timme S, Hoeppner J, Ostendorp J, Hembach S, Follo M, Hopt UT, Werner M, Busch H, Boerries M, et al: Selective inhibition of esophageal cancer cells by combination of HDAC inhibitors and Azacytidine. Epigenetics 10: 431-445, 2015.

36. Shi YK, Li ZH, Han XQ, Yi JH, Wang ZH, Hou JL, Feng CR, Fang QH, Wang HH, Zhang PF, et al: The histone deacetylase inhibitor suberoylanilide hydroxamic acid induces growth inhibition and enhances taxol-induced cell death in breast cancer. Cancer Chemother Pharmacol 66: 1131-1140, 2010.

37. Zhou C, Qiu L, Sun Y, Healey S, Wanebo H, Kouttab N, Di W, Yan B and Wan Y: Inhibition of EGFR/PI3K/AKT cell survival pathway promotes TSA's effect on cell death and migration in human ovarian cancer cells. Int J Oncol 29: 269-278, 2006.

38. Liu JJ, Lin B, Hao YY, Li FF, Liu DW, Qi Y, Zhu LC, Zhang SL and Iwamori M: Lewis(y) antigen stimulates the growth of ovarian cancer cells via regulation of the epidermal growth factor receptor pathway. Oncol Rep 23: 833-841, 2010. 